\title{
Correction: Mesenchymal stem cells derived extracellular vesicles improve behavioral and biochemical deficits in a phencyclidine model of schizophrenia
}

Hadas Tsivion-Visbord, Nisim Perets, Tamar Sofer (B), Lior Bikovski, Yona Goldshmit, Aangela Ruban and Offen Daniel (1)

Correction to: Translational Psychiatry https://doi.org/10.1038/s41398-020-00988-y, published online 1 September 2020

In the original Article, two author's names were misspelled/misstated: Dr. Angela Ruban's name was pre- viously misspelled as "Aangela Ruban", and Dr. Daniel Offen's forename and surname were transposed. Both names have been corrected in the PDF, HTML, and XML versions of this Article.

Published online: 22 September 2020 